\title{
BMJ Open Quality Improving mortality outcomes in aspiration pneumonia: training, technology and teamwork
}

Divya Tiwari, ${ }^{1,2}$ Ruth Kitchener, ${ }^{1}$ Sebastian Richards-Taylor, ${ }^{1}$ Martina Whiffen, ${ }^{1}$ Stephen Allen ${ }^{1,2}$

To cite: Tiwari D, Kitchener R, Richards-Taylor S, et al. Improving mortality outcomes in aspiration pneumonia: training, technology and teamwork. BMJ Open Quality 2022;11:e001553. doi:10.1136/ bmjoq-2021-001553

Received 11 May 2021 Accepted 8 September 2021

Check for updates

(C) Author(s) (or their employer(s)) 2022. Re-use permitted under CC BY-NC. No commercial re-use. See rights and permissions. Published by BMJ.

${ }^{1}$ Department of Older People Services, University Hospitals Dorset NHS Foundation Trust, Bournemouth, UK

${ }^{2}$ Faculty of Healh \& Social Sciences, Bournemouth University, Poole, UK

Correspondence to

Dr Divya Tiwari;

dtiwari@doctors.org.uk

\section{INTRODUCTION}

Aspiration is the inhalation of oropharyngeal or gastric content into the respiratory tract. ${ }^{1}$ The consequent clinical pattern depends on the patient's response, the quantity and frequency of aspiration, and the presence of pathogens. Two main clinical syndromes ensue. First, aspiration pneumonitis from chemical lung injury by sterile acidic gastric content, usually associated with patients with a reduced conscious level, ${ }^{2}$ and aspiration pneumonia from inhalation of colonised oropharyngeal material resulting in an inflammatory response to the bacteria. Many healthy individuals aspirate small amounts, mainly when asleep, that are cleared by ciliary transport, coughing and other lung defence systems. ${ }^{3}$ Aspiration pneumonitis or pneumonia (AP) usually occurs when those mechanisms are impaired, for example, by cerebrovascular disease, or overwhelmed by aspiration at higher volume. ${ }^{14}$ Optimal care of patients at risk of AP requires a multidisciplinary team approach ${ }^{5}$ involving individualised assessments and actions by doctors, nurses, speech and language therapists (SALTs), physiotherapists and others.

This Trust received an alert in 2015 from Care Quality Commission/Dr Foster system indicating that deaths in the category involving AP in 2012/2013 and 2014/2015 were higher than expected after standardisation. ${ }^{6}$ This prompted a structured retrospective mortality review (SRMR) in 2015, corrective actions, and further SRMRs in 2018 and 2020. As a subset of the Trust's wider mortality review data were collected salient to AP. This initiated three plan-dostudy-act (PDSA) cycles aimed at improving AP mortality, the processes and results of which are the topic of this paper.

\section{MIETHODS}

Three SRMRs were performed in 2015 (2011/2012 AP data), 2018 (2016/2017 AP data) and 2020 (2018/2019 AP data). Patient data were identified through the Trust audit office and from Dr Foster. Each patient's coding and death certificate were reviewed to determine whether they met the criteria for AP. Included cases were assessed against agreed criteria encompassing medical, nursing and other clinical care, SALT assessment and actions, and communication with the patient and family. Interventions based on extant best practice standards ${ }^{5}$ were implemented in order to reduce deaths due to AP.

\section{INTERVENTIONS}

The initial PDSA (2015), in response to the first SRMR, altered nursing care, emphasising feeding in a more upright position. Other measures included training by SALTs of ward staff on feeding and mouth care, the appointment of ward mouth care champions, training in safe feeding for healthcare assistants during their induction and adherence to Trust antibiotic policies. The second PDSA (2016), focused on timely SALT input, including at weekends, through online referral enabling two times per day triage. This was achieved through a business case for weekend SALT services. A personalised feeding-at-risk (FAR) proforma was produced containing the rationale for FAR decisions and advice on optimum food and drink consistency. This reduced ambiguity of care so subsequent clinicians would be clear about the feeding plan. The third PDSA (2017) aimed to improve communication between hospital and community SALT teams through using the discharge summary as a multidisciplinary document. 
User: Divya Tiwari

Participant: The Royal Bournemouth and Christchurch Hospitals NHS Foundation Trus

Report date: Thu Aug 062020 12:20:57

Url: $\quad$ https://one. drfoster.com/Query/?id $=1821415$

Basket: HSMR Metric: Mortality (in-hospital) Time period: Jan-11 to most recent

Diagnosis chapter: Respiratory Diagnosis group: Aspiration pneumonitis, food/vomitus

Patients: 567 Superspells: 615 (108.5) First / Last: Jan 2011 / Mar 2020 Deaths: 203 (33.0\%) Los: 12.8

Expected: 210.3 (34.2\%) O-E: -7.3 (-1.2\%) Relative Risk: 96.5 (83.7âc"110.8) Model: Month: Dec 2019 C-Statistic: 0.72 (Average) Model cases: 189271 Model deaths: 59660 Adjustment: Variables

Aspiration pneumonitis, food/vomitus | Mortality (in-hospital) | Jan-11 to most recent | Trend (financial year)

Diagnosis chapter: Respiratory| Diagnosis group: Aspiration pneumonitis, food/vomitus

Period: Financial year

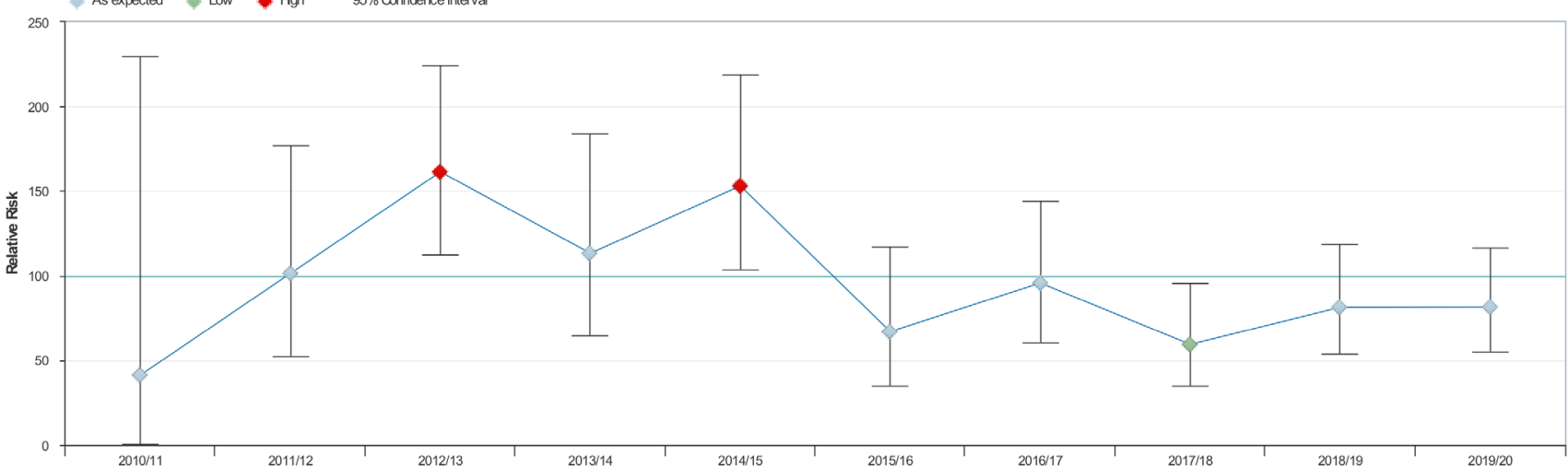

\begin{tabular}{|c|c|c|c|c|c|c|c|c|c|c|c|}
\hline Trend (financial year) & Superspells & $\%$ of All & Spells & Observed & Crude rate (\%) & Expected & Expected rate (\%) & Observed-expected & Relative risk & $95 \%$ lower confidence limit & $95 \%$ upper confidence limit \\
\hline All & 615 & $100.0 \%$ & 616 & 203 & $33.0 \%$ & 210.3 & $34.2 \%$ & -7.3 & 96.5 & $\begin{array}{r}83.7 \\
\end{array}$ & 110.8 \\
\hline 2010/11 & 6 & $1.0 \%$ & 6 & 1 & $16.7 \%$ & 2.4 & $40.4 \%$ & -1.4 & 41.3 & 0.5 & 229.7 \\
\hline $2011 / 12$ & 28 & $4.6 \%$ & 28 & 12 & $42.9 \%$ & 11.8 & $42.3 \%$ & 0.2 & 101.3 & 52.3 & 177.0 \\
\hline $2012 / 13$ & 54 & $8.8 \%$ & 54 & 35 & $64.8 \%$ & 21.7 & $40.2 \%$ & 13.3 & 161.3 & 112.4 & 224.4 \\
\hline $2013 / 14$ & 34 & $5.5 \%$ & 34 & 16 & $47.1 \%$ & 14.1 & $41.6 \%$ & 1.9 & 113.2 & 64.7 & 183.9 \\
\hline $2014 / 15$ & 51 & $8.3 \%$ & 51 & 30 & $58.8 \%$ & 19.6 & $38.4 \%$ & 10.4 & 153.0 & 103.2 & 218.4 \\
\hline $2015 / 16$ & 52 & $8.5 \%$ & 52 & 12 & $23.1 \%$ & 17.9 & $34.5 \%$ & -5.9 & 66.9 & 34.5 & 116.9 \\
\hline $2016 / 17$ & 64 & $10.4 \%$ & 64 & 23 & $35.9 \%$ & 24.0 & $37.6 \%$ & -1.0 & 95.7 & 60.6 & 143.6 \\
\hline $2017 / 18$ & 95 & $15.4 \%$ & 95 & 17 & $17.9 \%$ & 28.6 & $30.1 \%$ & -11.6 & 59.4 & 34.6 & 95.1 \\
\hline $2018 / 19$ & 108 & $17.6 \%$ & 109 & 27 & $25.0 \%$ & 33.2 & $30.7 \%$ & -6.2 & 81.3 & 53.6 & 118.3 \\
\hline $2019 / 20$ & 123 & $20.0 \%$ & 123 & 30 & $24.4 \%$ & 36.8 & $29.9 \%$ & -6.8 & 81.5 & 55.0 & 116.3 \\
\hline
\end{tabular}

Figure 1 Graph depicting Dr Foster mortality data for this hospital from 2011 to 2020. Diagnosis group: aspiration pneumonitis, food/vomitus. Copyright Dr Foster Limited, registered company number 3812015.

\section{RESULTS}

The Dr Foster mortality data for AP from 2011 to 2020 are shown in figure 1 . Alerts were triggered in 2012/2013 and $2014 / 2015$, with a relative risk of mortality of $161(95 \%$ CI 112 to 224) and 153 (95\% CI 103 to 218), respectively. The Trust's AP mortality fell after the initial interventions to 67 (95\% CI 35 to 117) in 2015/2016 and has remained below the national average for 5 consecutive years.

\section{SRIMR FINDINGS}

In 2015, 15 AP deaths met the inclusion criteria. Eleven had conditions predisposing to dysphagia. Of these, two patients had documented community feeding plans. Data were scanty with regard to SALT review, but of the five patients in which this was intended, only one was referred. No FAR conversations were documented.

In 2018, 10 deaths were confirmed in the AP category. Eight had conditions predisposing to dysphagia, all of whom were reviewed by SALT within 24 hours of referral. One was not referred, and one was too drowsy for assessment. All but one were referred on day 1 or 2 of admission. FAR discussions were held in all but one.

In 2020, nine AP deaths met the criteria. All were reviewed by SALT within 24 hours except one who died soon after admission. Five had pre-existing dietary modifications. Of the patients reviewed by SALT, only two did not have a documented FAR conversation.

\section{DISCUSSION}

Aspiration increases morbidity and mortality. The early assessment and active Multidisciplinary Team management we initiated at the first SRMR-guided PDSA were associated with a reduction in mortality from AP with sustained improvement associated with the further two PDSA cycles. The critical success factor appeared to be the collaborative MDT approach, focusing on nursing care, communication, early referral and early decision making. Though the number of patients was low, the clear temporal relationship between the interventions and the sustained improvement suggests a real effect and illustrates the utility of SRMR to generate information and PDSA to achieve change. Many of the patients had comorbidities associated with dysphagia, so perhaps a further PDSA could test the benefit of formal swallow assessments for all such patients, resources allowing, even if they present with no apparent aspiration. 


\section{Limitations}

Mortality ratios were monitored to evaluate the improvements. Therefore, direct attribution is not possible, although plausible.

Contributors DT: lead investigator and Trust mortality lead. RK, SR-T: coinvestigators and specialist registrars. MW: coinvestigator and speech and language therapist. SA: professor and senior investigator.

Funding The authors have not declared a specific grant for this research from any funding agency in the public, commercial or not-for-profit sectors.

Competing interests None declared.

Patient and public involvement Patients and/or the public were not involved in the design, conduct, reporting or dissemination plans of this research.

Patient consent for publication Not applicable.

Ethics approval This study does not involve human participants.

Provenance and peer review Not commissioned; externally peer reviewed.

Open access This is an open access article distributed in accordance with the Creative Commons Attribution Non Commercial (CC BY-NC 4.0) license, which permits others to distribute, remix, adapt, build upon this work non-commercially, and license their derivative works on different terms, provided the original work is properly cited, appropriate credit is given, any changes made indicated, and the use is non-commercial. See: http://creativecommons.org/licenses/by-nc/4.0/.

\section{REFERENCES}

1 Marik PE. Aspiration pneumonitis and aspiration pneumonia. $N$ Engl $J$ Med Overseas Ed 2001;344:665-71.

2 Marik PE. Pulmonary aspiration syndromes. Curr Opin Pulm Med 2011;17:148-54.

3 Marik PE, Kaplan D. Aspiration pneumonia and dysphagia in the elderly. Chest 2003;124:328-36.

4 Mandell LA, Niederman MS. Aspiration pneumonia. New England Journal of Medicine 2019;380:651-63.

5 Scottish Intercollegiate Guidelines Network. Management of patients with stroke: identification and management of dysphagia. Edinburgh: SIGN, 2010.

6 Cecil E, Wilkinson S, Bottle A, et al. National hospital mortality surveillance system: a descriptive analysis. BMJ Qual Saf 2018;27:974-81. 